\title{
The Effect of Formulation, Dose, and Adjuvants on Uptake of Phosphite Into Pine Foliage
}

Carol A. Rolando, ${ }^{\dagger}$ Scion, Fenton Park, Rotorua, New Zealand; Robyn E. Gaskin, Plant Protection Chemistry, Rotorua, New Zealand; Stefan F. Gous, HeliResources, Rotorua, 3040, New Zealand; David B. Horgan, Plant Protection Chemistry, Rotorua, New Zealand; and Laura G. Raymond, Scion, Fenton Park, Rotorua, New Zealand

\begin{abstract}
The aim of this investigation was to determine the effect of dose and adjuvant on uptake of two phosphite products (Phos-A and Phos-B) into Pinus radiata needles. In experiment 1, uptake of $6 \mathrm{~kg} \mathrm{ha}^{-1}$ phosphite, applied as Phos-A, in 100 liters of water, together with an organosilicone superspreader $(0.2 \%)$, was high $(>60 \%)$. Uptake at doses greater than $6 \mathrm{~kg} \mathrm{ha}^{-1}\left(12,15,18\right.$, and $\left.24 \mathrm{~kg} \mathrm{ha}^{-1}\right)$ and applied in volumes less than 100 liters of water (75 and 50 liters) was poor ( 1 to $30 \%$ ). Using stability tests and NMR spectroscopy in experiment 2, this appeared to be linked to a concentration dependent reaction resulting in the degradation of the organosilicone adjuvant that facilitated uptake

of Phos-A. In experiment 3, uptake of phosphite applied as Phos-B, between 6 and $24 \mathrm{~kg} \mathrm{ha}^{-1}$ in 100 liters of water, was tested alone and with four adjuvants (an organosilicone, alcohol ethoxylate, lecithin, and esterified seed oil). Uptake of Phos-B without any adjuvant was high $(>50 \%)$ across all doses, indicating the formulation was optimized for $P$. radiata needles. Uptake of Phos-B increased with concentration up to $72 \%$ at $24 \mathrm{~kg} \mathrm{ha}^{-1}$ in 100 liters of water. Symptoms of phytotoxicity were observed at rates of $\geq 12 \mathrm{~kg} \mathrm{ha}^{-1}$. This study highlighted the effect of formulation, dose, concentration, and adjuvant on the uptake of phosphite into $P$. radiata needles.
\end{abstract}

One of the most important ways to improve the efficacy of foliar applied pesticides is through increasing the penetration of the active ingredient into plant foliage (Wang and Liu 2007). The foliar uptake of active ingredients from pesticides is complex and involves processes that are influenced by environmental factors such as temperature, wind, and humidity (Baur 1998; Wang and Liu 2007). Other deterministic factors include droplet size, spray retention, leaf surface wettability, spreading, residue formation, and rates of foliar penetration (Baur 1998). Adjuvants can increase foliar penetration of pesticides, even when added to formulated products, mainly through their effect on factors such as droplet size, distribution, adhesion, spreading, wetting, and uptake (Baur 1998; Gent et al. 2003). For maximum efficacy of any plant protection product to be achieved, the interaction of a number of factors therefore needs to be optimized. Research into the foliar penetration of agrochemicals, including adjuvant chemistry, has focused on herbicide performance with fewer studies investigating penetration and uptake of fungicides (Gent et al. 2003; Stevens 1993). Fungicide utility and efficacy can be significantly enhanced by the use of adjuvants (Gent et al. 2003).

Phosphorous acid, or phosphite, is used widely in agriculture and horticulture to control a range of oomycete pathogens, including economically important Phytophthora species (Kanaskie et al. 2011; Rebollar-Alviter et al. 2007; Shearer and Crane 2009). Many studies document concentration of phosphite in plant tissues, biological activity in-planta, and efficacy at controlling disease (Borza et al. 2014; Kanaskie et al. 2011; Pilbeam et al. 2000; Thao and Yamakawa, 2009; Tynan et al. 2001). However, fewer studies have examined the efficiency of uptake of foliar applied phosphite into plant tissues

${ }^{\dagger}$ Corresponding author. E-mail: carol.rolando@ @scionresearch.com

CR, RG, and SG conceived and designed the research. DH and RG conducted experiments and LR conducted NMR spectroscopy. CR and RG wrote the manuscript and all authors read and approved the manuscript.

*The $\boldsymbol{e}$-Xtra logo stands for "electronic extra" and indicates that one supplementary table is published online.

Accepted for publication 16 May 2017.

C) 2017 The American Phytopathological Society and mechanisms that enhance or impair this process. Rolando et al. (2014) tested the effect of four commercially available adjuvants on uptake of a commercial formulation of phosphite into Pinus radiata D. Don foliage. An organosilicone blend adjuvant applied at $0.2 \%$ was found to significantly enhance the uptake of the active ingredient when applied in combination with the tested commercial formulation. At the equivalent of $12 \mathrm{~kg} \mathrm{ha}^{-1}$ phosphite, the adjuvant increased uptake of the active ingredient into $P$. radiata foliage ninefold, from 3.9 to $36.9 \%$ (Rolando et al. 2014). This was a significant outcome since many studies have shown that higher tissue concentrations of phosphite, up to a threshold concentration where either no further increase in efficacy occurs or phytotoxic effects become evident, improve the control of Phytophthora associated diseases, and the persistence of efficacy (Borza et al. 2014; Shearer and Fairman 2007). Higher uptake of active ingredient at any one dose means optimum tissue concentrations of the active ingredient can be achieved at lower application doses, reducing application costs and environmental inputs.

Phosphite is being investigated as a potential fungicide for the control of the disease red needle cast in planted $P$. radiata (radiata pine) forests in New Zealand, caused by Phytophthora pluvialis Reeser, W.L. Sutton and E.M. Hansen (Dick et al. 2014; Rolando et al. 2014). In-planta studies using a mix of a commercial formulation of phosphite applied together with an organosilicone adjuvant $(0.2 \%)$ have resulted in reduced infection of radiata pine needles (Rolando et al. 2014, 2017). However, no increase in efficacy of the active ingredient against $P$. pluvialis has yet been observed with increasing application dose ( $3 \mathrm{~kg} \mathrm{ha}^{-1}$ to $24 \mathrm{~kg} \mathrm{ha}^{-1}$ ) (Rolando et al. 2017). An effective treatment requires optimization of a number of factors including application dose, uptake, and translocation of active ingredient. The aim of this research was to determine the effect of formulation, dose, and adjuvant combination on the uptake of phosphite into radiata pine needles. This information was needed to identify the best formulation and adjuvant combination required to develop recommendations for an operational disease management program for red needle cast in radiata pine.

\section{Materials and Methods}

Experiment 1: Effect of dose rate, spray volume, and adjuvant on uptake of Phos-A. The penetration characteristics of phosphite (Phos-A, Agri-Fos 600, $600 \mathrm{~g} \mathrm{liter}^{-1}$ phosphite, Key Industries Ltd, New Zealand) at $24 \mathrm{~h}$ after treatment (HAT), applied at various 
doses and in combination with two adjuvants, was tested in this experiment (Table 1). Phosphite was applied to needles of radiata pine grafted clones as Phos-A at rates of $6,12,15,18$, and $24 \mathrm{~kg} \mathrm{ha}^{-1}$ in 50, 75 , and 100 liters ha ${ }^{-1}$ water in combination with an organosiliconeblend superspreader (hereafter referred to as the superspreader) containing siloxane polyalkeneoxide copolymers applied at the equivalent of $200 \mathrm{ml} \mathrm{ha}^{-1}$ across treatments (Du-Wett, Etec Crop Solutions Ltd, New Zealand). The second adjuvant, an organosilicone-blend superspreading sticker (hereafter referred to as the sticker) containing organosilicone and latex, was tested at the same rates of phosphite but only in 100 liters of water at the equivalent of $400 \mathrm{ml} \mathrm{ha}^{-1}$ across treatments (Du-Wett WeatherMax Etec Crop Solutions Ltd, New Zealand). The superspreader was shown to provide the highest uptake of phosphite in previous studies with Phos-A (Rolando et al. 2014). The sticker was included in this study as it could provide the additional benefit of rain proofing the highly water-soluble active ingredient (Gaskin and Steele 2009). The $\mathrm{pH}$ of all treatments was in the range of 6.0 to 6.2. Radiolabeled othophosphoric acid was used in all penetration studies and applied to all test needles as described in Rolando et al. (2014). Treatments were applied to foliage within $30 \mathrm{~min}$ to $2 \mathrm{~h}$ of mixing.

Briefly, orthophosphoric acid radio-labeled with $\left[{ }^{32} \mathrm{P}\right]$ (ARC, Inc., U.S.A.) was added to freshly prepared treatment solutions (Table 1) in deionized water $30 \mathrm{~min}$ prior to use to enable equilibration with the mono- and di-potassium salts present in the commercial phosphite formulation. Using a mycrosyringe, 10 droplets $(0.24 \mu \mathrm{l})$ of the radiolabeled treatment solution were applied to a single needle per fascicle such that they simulated either a 50,75 , or 100 liters ha $^{-1}$ spray application volume (i.e., 0.5 to $1 \mu \mathrm{cm}^{-2}$ ).

For each treatment, the quantity of radiolabeled phosphite applied to the needle was determined by dispensing droplets into scintillation vials (three replicates). Needle fascicles were harvested at 24 HAT when the entire fascicle was washed with a mixture of water and ethanol $(1: 1 \mathrm{v} / \mathrm{v} ; 2 \times 4 \mathrm{ml})$ to recover any unabsorbed phosphite. Scintillant solution (13 ml ACS; Amersham Biosciences, Australia) was added to the washings and radioactivity was quantified by liquid scintillation counting (Packard Tricarb 2100 TR). Foliar uptake was defined as the radioactivity not recovered from the wash and was calculated as a percentage of the applied dose.

Two clones of grafted radiata pine, Clone A and Clone B ( $\sim 2$ years with plant height $<1 \mathrm{~m}$ ), were used in this experiment. Clones were maintained and watered to holding capacity in free-draining pots (4.6 liters) at the Scion nursery (Rotorua, New Zealand) through late January 2014 (midsummer), after which selected plants were equilibrated for 2 weeks in a controlled environment cabinet $\left(23 / 18^{\circ} \mathrm{C}\right.$,
$70 \%$ relative humidity, $15 \mathrm{~h}$ photoperiod, $500 \mu \mathrm{mol} \mathrm{m} \mathrm{m}^{-2} \mathrm{sec}^{-1}$ light). After the 2 week equilibration period, all treatments were applied to 1 -year-old needles located on the main leader of the potted plants. There were three potted plants of each clone used for each treatment, such that all treatments were replicated on six plants (two clones $x$ three potted plants of each clone).

To ensure reproducibility, a number of treatments were selected from the treatment matrix and repeated. The two experiments are referred to as part 1 and part 2. The treatments tested in the repeat (part 2) of this experiment (Table 1) were applied within 15 to 30 min of preparation and therefore, part 2 differed only from part 1 in that
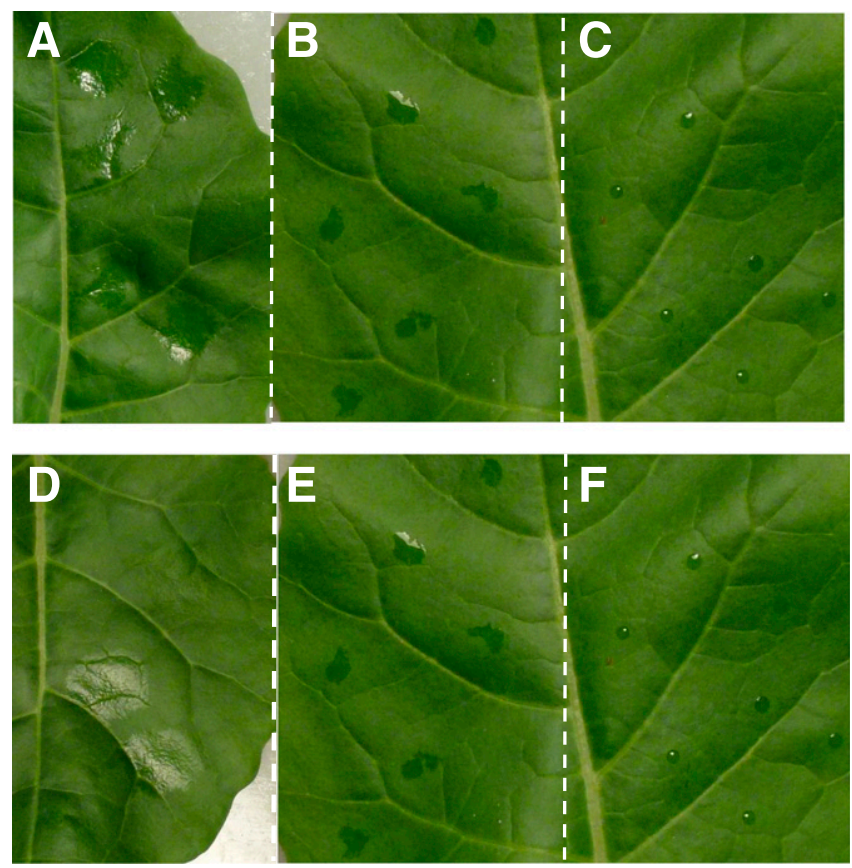

Fig. 1. Effect of phosphite applied as Phos-A on the spreading properties of the superspreader applied to waxy broccoli leaves: (a) $0.2 \%$ adjuvant; (b) $0.2 \%$ adjuvant + $12 \mathrm{~kg} \mathrm{ha}^{-1}$ phosphite applied 2 min within preparation; (c) $0.2 \%$ adjuvant $+12 \mathrm{~kg} \mathrm{ha}^{-1}$ phosphite applied $1 \mathrm{~h}$ after preparation; (d) $0.4 \%$ adjuvant; (e) $0.4 \%$ adjuvant $+12 \mathrm{~kg}$ $\mathrm{ha}^{-1}$ phosphite applied within 2 min of preparation; (f) $0.4 \%$ adjuvant $+12 \mathrm{~kg} \mathrm{ha}^{-1}$ phosphite applied $1 \mathrm{~h}$ after preparation.

Table 1. Percentage uptake of $\left[{ }^{32} \mathrm{P}\right]$ phosphite (experiment 1$)$ applied as Phos-A into radiata pine needles with the superspreader (200 $\left.\mathrm{ml} / \mathrm{ha}\right)$ and sticker (400 $\left.\mathrm{ml} / \mathrm{ha}\right)$ adjuvants at 24 hours after treatment (HAT). Treatments applied within 0.5 to $2 \mathrm{~h}$ of mixing and within $0.5 \mathrm{~h}$ of mixing for part 1 and part 2 , respectively. Means within each part of experiment 1 sharing common postscripts are not significantly different at $P<0.05$ ( \pm indicates standard error). Shaded cells are those that were not repeated in part 2 of experiment $1 .^{\mathrm{z}}$

\begin{tabular}{|c|c|c|c|c|}
\hline \multirow[b]{4}{*}{ Phosphite $\left(\mathrm{kg} \mathrm{ha}^{-1}\right)$} & \multicolumn{4}{|c|}{ Spray application volume } \\
\hline & \multicolumn{4}{|c|}{ Adjuvant concentration (w/v) } \\
\hline & 100 liters ha $^{-1}$ & 75 liters ha $^{-1}$ & 50 liters ha ${ }^{-1}$ & 100 liters ha ${ }^{-1}$ \\
\hline & $\overline{\text { Superspreader } 0.2 \%}$ & $\overline{\text { Superspreader } 0.27 \%}$ & $\overline{\text { Superspreader } 0.4 \%}$ & Sticker $0.4 \%$ \\
\hline \multicolumn{5}{|l|}{ Part 1: experiment 1} \\
\hline 6 & $62 \pm 13 a$ & $33 \pm 10 b$ & $18 \pm 4$ cde & $49 \pm 32 \mathrm{a}$ \\
\hline 12 & $12 \pm 9$ defg & $4 \pm 3$ efg & $4 \pm 4 \mathrm{fg}$ & $2 \pm 1 \mathrm{~g}$ \\
\hline 15 & $23 \pm 20 \mathrm{bcd}$ & $11 \pm 8$ defg & $1 \pm 2 g$ & $4 \pm 2 \mathrm{fg}$ \\
\hline 18 & $12 \pm 11$ defg & $31 \pm 20 b c$ & - & $5 \pm 3 \mathrm{efg}$ \\
\hline 24 & $11 \pm 9$ defg & $17 \pm 16$ defg & - & $2 \pm 1 \mathrm{~g}$ \\
\hline \multicolumn{5}{|l|}{ Part 2: experiment 1} \\
\hline 6 & $53 \pm 3 a b$ & $55 \pm 11 \mathrm{ab}$ & $59 \pm 6 a$ & $40 \pm 34 a b c$ \\
\hline 12 & $56 \pm 3 a b$ & $* 30 \pm 23 \mathrm{bc}$ & $* 55 \pm 29 \mathrm{ab}$ & - \\
\hline 15 & $* 26 \pm 35 \mathrm{c}$ & $* 56 \pm 38 \mathrm{ab}$ & $* 16 \pm 23 \mathrm{c}$ & - \\
\hline 18 & $* 15 \pm 16 \mathrm{c}$ & - & - & - \\
\hline 24 & $* 14 \pm 18 \mathrm{c}$ & - & - & - \\
\hline
\end{tabular}

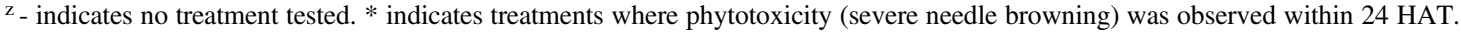


solutions were applied to the needles in less than $30 \mathrm{~min}$ of preparation as opposed to $2 \mathrm{~h}$. Treatments were applied, harvested at 24 HAT, and processed as described above.

Experiment 2: Interactions of Phos-A with organosilicone adjuvants. Solutions of Phos-A (Table 1, Supplementary Table S1) were made up with either the superspreader or sticker used in experiment 1 and visually monitored for stability from 5 to 60 min postmixing. Spreading of selected solutions was also visualized on waxy broccoli (Brassica oleracea L.) leaves to monitor any chemical breakdown of the adjuvants, as indicated by the effect on superspreading (Policello et al. 1995).

Nuclear magnetic resonance spectroscopy (NMR) was used to investigate the stability of solutions of Phos-A (applied at the equivalent of 6 and $12 \mathrm{~kg} \mathrm{ha}^{-1}$ phosphite in 100 liters of water) prepared with and without the organosilicone superspreader at $0.2 \% . \mathrm{D}_{2} \mathrm{O}$ was used as a lock solvent that also contained TSP (sodium salt of 3-[trimethylsilyl]-propionate acid- $d_{4}$ ) at $0.05 \% \mathrm{w} / \mathrm{v}$ as an internal standard. Treatments were made up to $1 \mathrm{ml}$ and a $600 \mu \mathrm{l}$ aliquot was transferred into $5 \mathrm{~mm}$ NMR tube for analysis.

One dimensional ${ }^{1} \mathrm{H}$ NMR spectra were acquired on a Bruker Avance III 400 NMR spectrometer using noesygppr1d pulse sequence in the Bruker pulse sequence library, with a presaturation power field of $33 \mathrm{~Hz}$ and transmitter frequency offset (o1) at $1,886.50 \mathrm{~Hz}$. The internal probe temperature was set to $300 \mathrm{~K}$. The spectral data were obtained in $65 \mathrm{~K}$ data points, a relaxation delay of $8 \mathrm{~s}$, and 64 scans. After Fourier transformation, NMR data were phase and baseline corrected and referenced to the TSP resonance at $0.0 \mathrm{ppm}$.

NMR spectra were acquired using the pulse sequence ZGPG30 with a relaxation delay of $2 \mathrm{~s}$ and 16 scans. After Fourier transformation, NMR data were phase and baseline corrected and referenced using $\mathrm{H}_{3} \mathrm{PO}_{4}$ at $0.0 \mathrm{ppm}$ as an external reference. ${ }^{1} \mathrm{H}$ NMR and ${ }^{31} \mathrm{P}$ NMR were acquired subsequently at time periods between initial mixing and monitored up to $24 \mathrm{~h}$.

Experiment 3: Effect of dose and adjuvant on stability and uptake of Phos-B. Following the results obtained with experiments 1 and 2, a decision was made to test an alternative formulation of phosphite, Phos-B (Foschek, $400 \mathrm{~g} \mathrm{liter}^{-1}$ phosphite, Zelam Ltd, New Zealand), to determine whether the same trends would be observed with respect to uptake and interaction with adjuvants. Solutions of Phos-B were prepared at three rates, 6,12 , and $24 \mathrm{~kg} \mathrm{ha}^{-1}$ phosphite, in 100 liters $\mathrm{ha}^{-1}$ of water. Phos-B differed from Phos-A in formulants (proprietary surfactants) and phosphite concentration; both products contained phosphorous acid as the mono- and di-potassium salts. Stability and uptake of Phos-B were determined for each solution and in combination with a single recommended concentration of each of four adjuvants. The $\mathrm{pH}$ of all treatments was in the range of 5.7 to 6.2. The four adjuvants investigated were (underlined text used

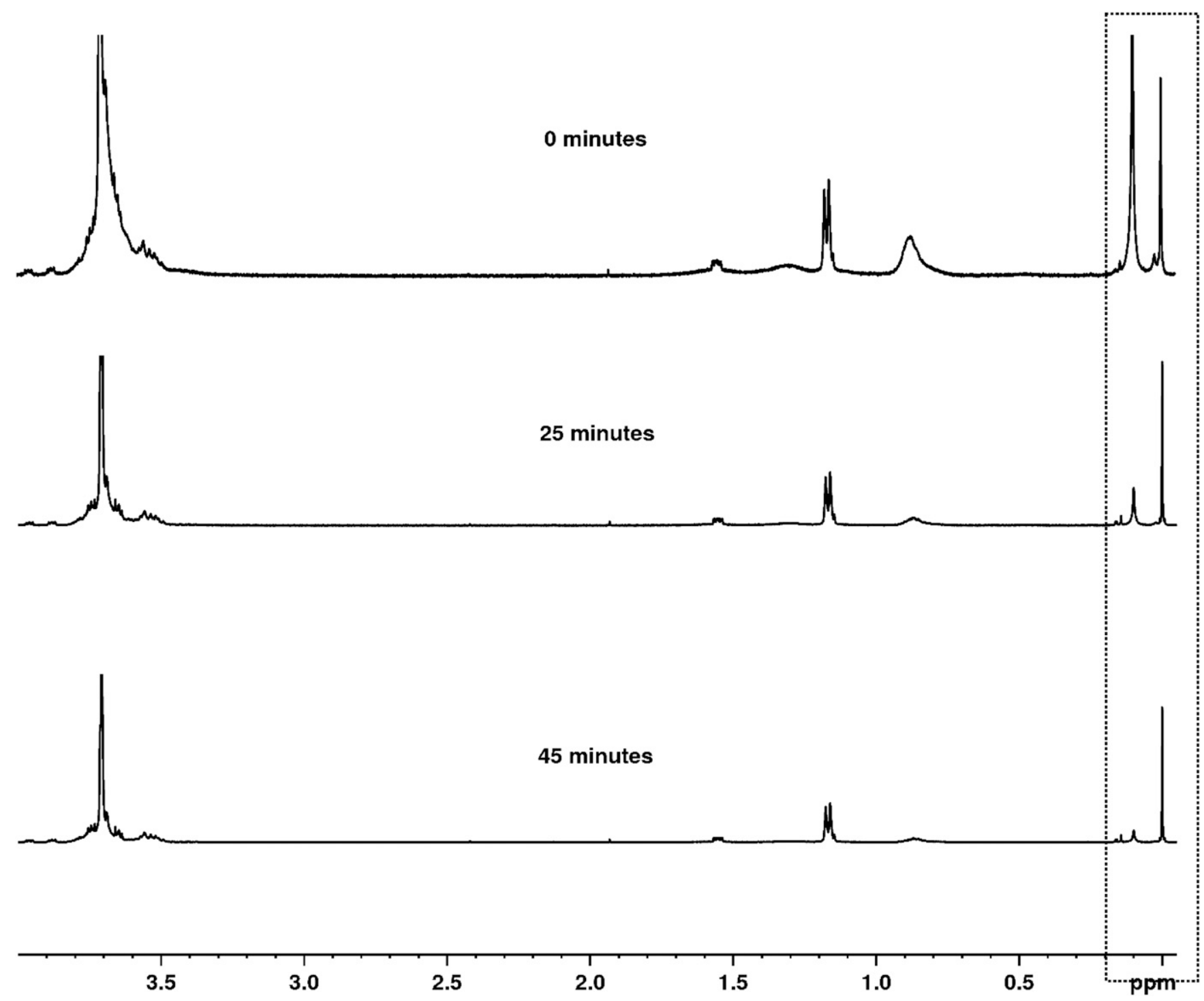

Fig. 2. ${ }^{1} \mathrm{H}$ NMR spectra ( 0 to $4 \mathrm{ppm}$ region) of the interaction between equivalent of $24 \mathrm{~kg} \mathrm{ha}^{-1}$ Phos-A in 100 liters of water and $0.2 \%$ organosilicone superspreader at times 0,25 , and $45 \mathrm{~min}$. 
in further reference to the treatment) i) a linear alcohol ethoxylate (Actiwett, Etec Crop Solutions Ltd, New Zealand) applied at $0.2 \%$, ii) a lecithin plus methyl esters of fatty acids and alcohol ethoxylate (LI-1000, Etec Crop Solutions Ltd, New Zealand) applied at 0.25\%, iii) a seed oil, a blend of esterified vegetable oil and nonionic surfactants (Hasten, BASF, New Zealand) applied at $0.25 \%$, and iv) an organosilicone-blend superspreader containing siloxane polyalkeneoxide copolymers (Du-Wett, Etec Crop Solutions Ltd, New Zealand) applied at $0.2 \%$.

For stability tests, solutions were made up in $20 \mathrm{ml}$ glass vials, with a total mix of $14 \mathrm{ml}$ in each vial so as to accurately assess the solution's stability. They were visually monitored from initial mixing (for the first $2 \mathrm{~h}$ after mixing) through to $24 \mathrm{~h}$ postmix. Droplets of the solutions were also applied onto cabbage (Brassica oleracea L. var. Matador) leaves as $5 \times 1 \mu \mathrm{l}$ droplets at initial mixing and $1 \mathrm{~h}$ and $24 \mathrm{~h}$ after mixing. Photographs of the droplets were taken to visually assess their spreading properties and to indicate if degradation of the adjuvants was occurring. All tests were carried out at $20^{\circ} \mathrm{C}$. As experiment 1 and experiment 3 were not conducted simultaneously, the spreading properties of the formulation and adjuvant combinations were not tested on the same plants. However, broccoli and cabbage plants have very similar difficult-to-wet leaves with an adaxial contact angle of $\sim 120^{\circ}$ (Gaskin et al. 2005). For determination of uptake, all treatments (three rates [Rate] of phosphite and four adjuvants [A]) were replicated three times on each of the two clones (Clone) of radiata pine, $\mathrm{A}$ and $\mathrm{B}$, as described for experiment 1 within 30 mins of mixing and uptake was determined at $24 \mathrm{HAT}$.

Statistical analyses. Treatments in experiments 1 and 3 were compared by two way analysis of variance and least significant difference (LSD) using the statistical program Statistix 9 (Analytical Software, U.S.A.). Variance stabilizing transformations were made where necessary prior to analysis.

\section{Results}

Experiment 1: Effect of dose rate, spray volume, and adjuvant on uptake of Phos-A. The results of part 1 of this experiment indicated that application of higher rates of phosphite $\left(>6 \mathrm{~kg} \mathrm{ha}^{-1}\right)$ within a constant spray volume generally reduced percentage foliar uptake. This trend was particularly evident at application volumes of 100 and 50 liters per hectare water where percentage uptake at $6 \mathrm{~kg} \mathrm{ha}^{-1}$ phosphite was significantly greater than that of higher doses (Table 1). Similarly, increasing the phosphite concentration within a spray dose, by reducing spray application volume, also reduced phosphite uptake, particularly significant at the $6 \mathrm{~kg} \mathrm{ha}^{-1}$ dose when applied at the equivalent of 100,75 , and 50 liters of water. For all treatments, variation between replicates was generally very high and uptake could vary by up to 15 -fold between needle replicates within a treatment, a factor which also reduced the power of the statistical tests.

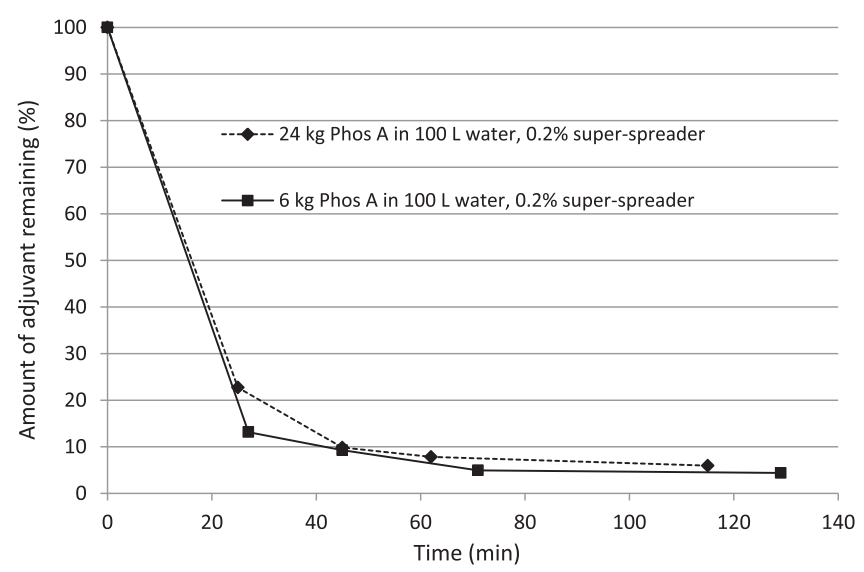

Fig. 3. Degradation of the organosilicone superspreader $(0.2 \%)$ as a percentage of starting amount of organosilicone in the presence of the equivalent of $6 \mathrm{~kg} \mathrm{ha}^{-1}$ $(6 \%)$ and $24 \mathrm{~kg} \mathrm{ha}^{-1}(12 \%)$ phosphite as Phos-A in 100 liters of water.
This effect was observed with both the superspreader and sticker adjuvant solutions (Table 1). During the application of treatments, it was also observed that very little superspreading of droplets occurred. At harvest, 24 HAT, most treatment droplets were still present on the needle surfaces in a discrete hydrated state, confirming the lack of spreading over time. No phytotoxicity was observed within 24 HAT in any treatments, which was not surprising given the low levels of uptake recorded.

Part 2 of this experiment was carried out to repeat the study and investigate the seemingly anomalous results of part 1 . There was a marked increase in the percentage uptake of phosphite at 6 and $12 \mathrm{~kg} \mathrm{ha}^{-1}$ across all application volumes when freshly prepared treatment solutions of Phos-A, applied within 30 min of mixing, were used (Table 1). Some increase in uptake was also observed for the $15 \mathrm{~kg}$ and 75 liters ha ${ }^{-1}$ treatment, but this was still associated with high variability in uptake. Uptake at the high application doses of 18 and $24 \mathrm{~kg} \mathrm{ha}^{-1}$ was still significantly lower than that below $15 \mathrm{~kg} \mathrm{ha}^{-1}$, with a variation in mass uptake of phosphite (\% uptake $x$ dose applied) of only threefold over all treatments. Phytotoxicity in part 2 was observed as concentration increased either within an application volume or across an application dose (Table 1), suggesting that a higher dose of phosphite in freshly prepared solutions penetrated faster and is more likely to damage cells. In contrast to part 1 , all treatments were observed to spread.

The only difference in treatment application between parts 1 and 2 of the experiment was in the time interval between treatment preparation and application.

Experiment 2: Interactions of Phos-A with organosilicone adjuvants. The stability of the sticker and superspreader adjuvants in the phosphite solutions of Phos-A was initially determined by visual observation. Within $1 \mathrm{~h}$ of mixing, all treatment solutions except the phosphite $\left(6 \mathrm{~kg} \mathrm{ha}^{-1}\right)$ solution with the sticker adjuvant $(0.4 \%)$ turned clear and deposited a viscous precipitate near the surface of the solution (Supplementary Table S1). By 17 HAT, all treatments were similarly clear, while solutions of adjuvant only (superspreader or sticker) remained typically opaque. The adjuvant degradation was confirmed by monitoring the spreading of the superspreader adjuvants alone, immediately upon mixing with Phos-A formulation and at $1 \mathrm{~h}$ after mixing, on a waxy broccoli leaf (Fig. 1). The spreading properties of the adjuvant were reduced by combining with the Phos-A formulation.

NMR spectroscopy was used to confirm whether a chemical interaction between phosphite, applied as Phos-A, and the organosilicone superspreader was occurring. Signals in the ${ }^{1} \mathrm{H}$ NMR spectra from the superspreader were found in the 0 to $4 \mathrm{ppm}$ region due to the trisiloxane ethoxylate, an alcohol ethoxylate and polyalkylene oxide (Fig. 2). The signal in the ${ }^{1} \mathrm{H}$ NMR spectra at $0.10 \mathrm{ppm}$ (highlighted by box in Figure 2) was attributed to the trisiloxane part of the trisiloxane ethoxylate. This signal decreased rapidly within the first 30 min of mixing the adjuvant with Phos-A, with no new formation of other signals. The same trend was seen for the adjuvant in the presence of the equivalent of 6 or $24 \mathrm{~kg} \mathrm{ha}^{-1}$ of Phos-A in 100 liters of water (Fig. 3). Most of the degradation occurred within the first $30 \mathrm{~min}$ and no major changes to the spectra were observed from $1 \mathrm{~h}$ to $24 \mathrm{~h}$. No changes in peak intensity from the signals due to Phos-A were observed in the ${ }^{1} \mathrm{H}$ NMR, suggesting that there was no degradation of Phos-A.

Table 2. Stability of Phos-B solutions used in experiment 3 as assessed by visual monitoring over 24 hours when applied with four different adjuvants at the equivalent of 6,12 , and $24 \mathrm{~kg} \mathrm{ha}^{-1}$ in 100 liters of water

\begin{tabular}{llll}
\hline & \multicolumn{3}{c}{ Concentration of phosphite } \\
\cline { 2 - 4 } Treatment & $\mathbf{6 ~ k g ~ h a} \mathbf{~}^{-\mathbf{1}}$ & $\mathbf{1 2} \mathbf{~ k g ~ h a}$ & $\mathbf{2 4} \mathbf{~ k g ~ h a}$ \\
\hline Phos-B alone & stable & stable & stable \\
+ alcohol ethoxylate $0.2 \%$ & stable & stable & stable \\
+ lecithin $0.25 \%$ & stable & stable & some instability \\
+ seed oil $0.25 \%$ & stable & stable & stable \\
+ organosilicone $0.2 \%$ & stable & stable & some instability \\
\hline
\end{tabular}


Experiment 3: Effect of dose and adjuvant on stability and uptake of Phos-B. The stability tests indicated that the Phos-B formulation was stable with all adjuvants tested over $24 \mathrm{~h}$ after mixing (Table 2). Only after $24 \mathrm{~h}$ with the highest rate of phosphite tested $\left(24 \mathrm{~kg} \mathrm{ha}^{-1}\right.$ ) were some clear viscous precipitates observed near the surface of the solutions containing the organosilicone and lecithin adjuvants, indicating adjuvant breakdown (Table 2). However, this did not seem to affect the droplet spreading in either of these treatments at $24 \mathrm{~h}$ (Fig. 4). Phos-B already contains surfactants in its formulation and it was observed that as the Phos-B rates increased, so did the droplet spreading. Generally the addition of adjuvants to Phos-B improved the droplet spreading on cabbage and the best

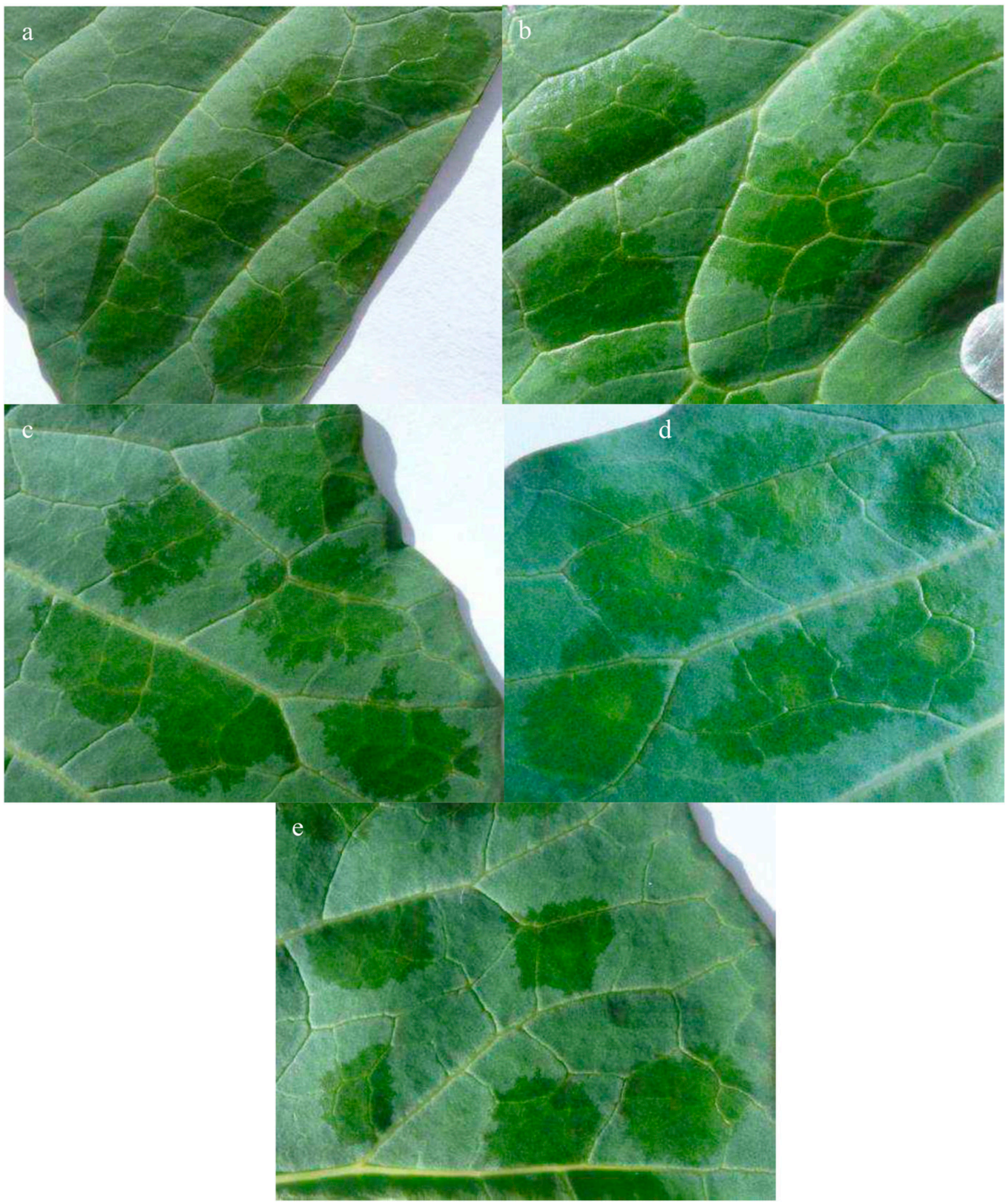

Fig. 4. Droplet spreading properties of Phos-B solutions when applied at $24 \mathrm{~kg} \mathrm{ha}^{-1}$ with (a) no adjuvant, (b) $0.2 \%$ organosilicone, (c) $0.2 \%$ alcohol ethoxylate, (d) $0.25 \%$ seed oil, and (e) $0.25 \%$ lecithin 
of these adjuvants was the organosilicone, and then the alcohol ethoxylate.

The second part of this study was undertaken to determine the uptake of phosphite into $P$. radiata needles when applied as Phos-B, over the dose range of 6 to $24 \mathrm{~kg} \mathrm{ha}^{-1}$, with and without the addition of penetrating adjuvants. Major effects examined were adjuvant (A), phosphite rate (Rate), and clonal (Clone) differences in uptake (Tables 3 and 4). The effect of adjuvant on phosphorus acid uptake was highly significant $(P<0.01)$, in the order: alcohol ethoxylate $=$ organosilicone $=$ no adjuvant $>$ seed oil $=$ lecithin $($ Table 3$)$. This indicated that Phos-B was sufficiently well adjuvanted not to require extra adjuvant addition to sprays to enhance uptake into radiata pine.

For Phos-B, the effect of phosphite rate on percentage uptake was highly significant $(P<0.01)$, in the order: $24 \mathrm{~kg} \mathrm{ha}^{-1}=12 \mathrm{~kg} \mathrm{ha}^{-1}>$ $6 \mathrm{~kg} \mathrm{ha}^{-1}$ (Table 3 and 4). Overall, uptake of phosphite from Phos-B (Table 4) was markedly better than from Phos-A (Table 1), with over $70 \%$ uptake of Phos-B at the highest dose $\left(24 \mathrm{~kg} \mathrm{ha}^{-1}\right)$. This effect on uptake with Phos-B was associated with observed phytotoxicity of treatments, where none was observed at $6 \mathrm{~kg} \mathrm{ha}^{-1}$ but was present, as brown spots at the site of droplet applications, in all treatments at 12 and $24 \mathrm{~kg} \mathrm{ha}^{-1}$.

The effect of clone on phosphorus acid uptake was highly significant $(P<0.001)$, in that uptake was consistently higher in Clone A $(65.8 \%)$ than in Clone B $(51.6 \%)$. Although both clones were healthy, Clone B needles were observed to be shorter in length and more prone to exhibit phytotoxicity than Clone A, despite the lower mean uptake in the former.

\section{Discussion}

In part 1 of experiment 1 , uptake with all concentrations of phosphite $>6 \mathrm{~kg} / \mathrm{ha}$ was generally poor and increasing the concentration of phosphite in the treatment solution, by reducing spray volume per hectare, also decreased uptake. The organosilicone adjuvants increased phosphite uptake, as has been previously shown on pine (Rolando et al. 2014), but uptake decreased as the superspreader adjuvant concentration increased. The lack of phytotoxicity in any treatment supported the low uptake results, but these were confounded by the probable degradation of the adjuvant in combination with the Phos-A formulation.

In part 2 of experiment 1 , solutions were applied to the needle within 30 min of preparation and prior to substantial adjuvant deactivation, as evidenced by superspreading of all treatments. Uptake of active ingredient at $<15 \mathrm{~kg} \mathrm{ha}^{-1}$ was substantially improved in

Table 3. Summary of the analysis of variance for the Phos-B uptake study conducted as part of experiment 3

\begin{tabular}{lccr}
\hline Source $^{\mathbf{z}}$ & DF & MS & $\boldsymbol{P}$-value \\
\hline A & 4 & $1,162.27$ & $<0.010$ \\
Rate & 2 & $1,496.96$ & $<0.010$ \\
Clone & 1 & $4,538.8$ & $<0.010$ \\
Rep & 2 & 17.66 & 0.780 \\
A*Rate & 8 & 202.32 & 0.001 \\
A*Clone & 4 & 328.9 & $<0.001$ \\
Rate*Clone & 2 & 87.19 & 0.300 \\
A*Rate*Clone & 8 & 106.18 & 0.178 \\
Error & 58 & 71.09 & \\
Total & 89 & & \\
\hline
\end{tabular}

${ }^{\mathrm{z}} \mathrm{A}=$ adjuvants, rate $=$ rate of phosphite, clone $=$ clone $\mathrm{A} / \mathrm{B}$. comparison with part 1 , while higher rates of active ingredient still reduced percentage uptake. Phytotoxicity was observed in all treatments where concentration of the active ingredient was greater than $12 \mathrm{~kg} \mathrm{ha}^{-1}$. The contrasting results in parts 1 and 2 (experiment 1 ) highlighted that: 1) a time and concentration dependent chemical interaction was occurring between Phos-A and the organosilicone adjuvants, and 2) potentially slower uptake of lower doses of phosphite (up to $12 \mathrm{~kg} \mathrm{ha}^{-1}$ in 100 liters of water) did not result in cell damage as indicated by the lack of phytotoxicity symptoms shown at the lower concentrations for part 2 of the experiment despite high rates of uptake $(>50 \%)$. As shown in part 2 , higher concentrations of active ingredient resulted in phytotoxicity only when applied while the adjuvant retained activity within the spray solution. Thus, it appears the organosilicone adjuvant has the potential to significantly enhance the speed of uptake of the active ingredient. The interaction that occurred between the adjuvant and Phos-A formulation, which was evidenced in droplet spreading tests, was confirmed by NMR spectroscopy (experiment 2) to result in rapid degradation (cleavage) of the trisiloxane ethoxylate after sample preparation. The results with NMR spectroscopy indicated there was cleavage between the ethoxylate and the trisiloxane, with the newly formed water insoluble trisiloxane precipitating out, and therefore "invisible" to solution state NMR.

Experiment 3 was carried out to determine whether a different formulation of phosphite would improve uptake into radiata pine needles when applied across a range of doses (6 to $\left.24 \mathrm{~kg} \mathrm{ha}^{-1}\right)$ with or without an adjuvant. Uptake of phosphite applied as Phos-B without any adjuvant addition was very high across all doses tested, indicating the formulation was already well optimized for uptake into radiata pine needles. Applied alone, uptake from Phos-B increased with increasing concentration up to a maximum of $72 \%$ when applied at the equivalent of $24 \mathrm{~kg} \mathrm{ha}^{-1}$, much higher than observed in experiment 1 and previous work with phosphite (Rolando et al. 2014). Mild symptoms of phytotoxicity were observed at rates of 12 and $24 \mathrm{~kg} \mathrm{ha}^{-1}$. While all adjuvants did not significantly benefit uptake, the organosilicone and alcohol ethoxylate may be useful to improve efficacy through other spray processes not tested in this study, such as adhesion and retention. This would need to be determined in further studies.

Genotype had a significant effect on uptake of phosphite in experiment 3 . The two clones differed in their susceptibility to infection with $P$. pluvialis, with clone A considered moderately susceptible to infection and clone B highly susceptible (Williams et al. 2015). Uptake of phosphite was significantly lower for clone B, the susceptible clone, with more symptoms of phytotoxicity also observed on the needles of this clone. This outcome aligns with existing inplanta studies that indicated efficacy of phosphite varied across clones of radiata pine (Rolando et al. 2017). Following treatment with phosphite, lesion number and length in detached needle assays with $P$. pluvialis were found to differ significantly between $P$. radiata clones. Larger lesions were measured on clones highly sensitive to the pathogen than on those categorized as more resistant across the same treatment dose (Rolando et al. 2017). Clonal, and species, variations in response to phosphite application have been measured in other studies (Pilbeam et al. 2011; Shearer and Fairman 2007), but these variations have not been related to a difference in uptake of active ingredient but rather a response at the physiological level (Pilbeam et al. 2011). Regardless of the mechanism driving the clonal variation in phosphite efficacy, further research is required to ensure operational spraying programs do not cause adverse phytotoxicity on sensitive clones.

Table 4. Uptake of $\left[{ }^{32} \mathrm{P}\right]$ phosphite into radiata pine needles at 24 hours after treatment (HAT) applied as Phos-B with a range of adjuvants in the equivalent of 100 liters ha $^{-1}$ water. Means sharing common postscripts are not significantly different at $P<0.05$. $^{\mathrm{z}}$

\begin{tabular}{llcccc}
\hline Phosphite $\left(\mathrm{kg} \mathrm{ha}^{-\mathbf{1}}\right)$ & No adjuvant & Alcohol ethoxylate 0.2\% & Lecithin 0.25\% & Seed oil 0.25\% & Organosilicone (0.2\%) \\
\hline 6 & $53.4 \mathrm{ef}$ & $59.4 \mathrm{cdef}$ & $35.0 \mathrm{~g}$ & $39.9 \mathrm{~g}$ & $65.3 \mathrm{abcd}$ \\
12 & $64.3 \mathrm{abcd} *$ & $72.4 \mathrm{a} * *$ & $51.6 \mathrm{f} *$ & $56.8 \mathrm{def} *$ & $62.6 \mathrm{bcde} *$ \\
24 & $71.9 \mathrm{ab} * *$ & $63.9 \mathrm{abcd} * *$ & $59.1 \mathrm{cdef} * *$ & $57.3 \mathrm{def}$ & $66.9 \mathrm{abc} * *$ \\
\hline
\end{tabular}

${ }^{\mathrm{z}}$ Phytotoxicity observed on treated needles: * very mild, ${ }^{* *}$ mild. 
The impact of formulation, and adjuvant chemistry, on uptake of pesticides is well described in the literature (Forster and Kimberley 2015; Green and Beestman 2007). This study has highlighted the differences formulation can make to the uptake of an active ingredient and the importance of screening a wide range of commercially formulated products in development of disease management strategies. The outcome also emphasizes the need to ensure that end users are aware of the impact of formulation on uptake such that recommendations are specific to a formulated product and adjuvant combination rather than only active ingredient.

This study has highlighted the significant effect of factors such as formulation, dose, concentration, and adjuvant on the rate and total amount of uptake of phosphite into radiata pine needles: either limiting (in the case of Phos-A) or increasing (in the case of Phos-B) uptake. While the impact of uptake on efficacy was not investigated in this study, the results showed that the concentration, formulation, and adjuvant combination could also increase the damage to target foliage, a factor which would be highly undesirable in any operational spray program. Overall, it appears from this study that $6 \mathrm{~kg} \mathrm{ha}^{-1}$ of phosphite applied as Phos-A or B in 50 to 100 liters of water is a "safe" rate to apply over radiata pine, as no phytotoxicity was observed at these rates. However, the relative efficacies, impacts, and cost-benefits of the different formulations, rates of application, and their performance in field are still under investigation.

\section{Acknowledgments}

This work was funded by the New Zealand Forest Owners Association via the Forest Growers Levy Trust.

\section{Literature Cited}

Baur, P. 1998. Mechanistic aspects of foliar penetration of agrochemicals and the effect of adjuvants. Recent Res. Dev. Agric. Food Chem. 2:809-837.

Borza, T., Schofield, A., Sakthivel, G., Bergese, J., Gao, X., Rand, J., and WangPruski, G. 2014. Ion chromatography analysis of phosphite uptake and translocation by potato plants: Dose-dependent uptake and inhibition of Phytophthora infestans development. Crop Prot. 56:74-81.

Dick, M. A., Williams, N. M., Karl-Friedrich, M. B., Gardner, J. F., and Bulman, L. S. 2014. Pathogenicity of Phytophthora pluvialis to Pinus radiata and its relation with red needle cast disease in New Zealand. N. Z. J. Sci. 44:6.

Forster, W. A., and Kimberley, M. O. 2015. The contribution of spray formulation component variables to foliar uptake of agrichemicals. Pest Manag. Sci. 71: 1324-1334.

Gaskin, R. E., and Steele, K. D. 2009. A comparison of sticker adjuvants for their effects on retention and rainfastening of fungicide sprays. N. Z. Plant Prot. 62:339-342.

Gaskin, R. E., Steele, K. D., and Forster, W. A. 2005. Characterising plant surfaces for spray adhesion and retention. N. Z. Plant Prot. 58:179-183.
Gent, D. H., Schwartz, H. F., and Nissen, S. J. 2003. Effect of commercial adjuvants on vegetable crop fungicide coverage, absorption, and efficacy. Plant Dis. 87:591-597.

Green, J. M., and Beestman, G. B. 2007. Recently patented and commercialized formulation and adjuvant technology. Crop Prot. 26:320-327.

Kanaskie, A., Hansen, E. M., Sutton, W., Reeser, P., and Choquette, C. 2011. Application of phosphonate to prevent sudden oak death in south-western Oregon tanoak (Notholithocarpus densiflorus) forests. N. Z. J. Sci. 41S: S177-S187.

Pilbeam, R. A., Colquoun, I. J., Shearer, B., and Hardy, G. E. S. J. 2000. Phosphite concentration: Its effect on phytotoxicity symptoms and colonisation by Phytophthora cinnamomi in three understorey species of Eucalyptus marginata forest. Australas. Plant Pathol. 29:86-95.

Pilbeam, R. A., Howard, K., Shearer, B. L., and Hardy, G. E. S. J. 2011. Phosphite stimulated histological responses of Eucalyptus marginata to infection by Phytophthora cinnamomi. Trees Struct. Funct. 25:1121-1131.

Policello, G. A., Stevens, P. J. G., Forster, W. A., and Murphy, G. J. 1995. The influence of $\mathrm{pH}$ on the performance of organosilicone surfactants. Pages 313-317 in: Pesticide Formulations and Application Systems: Fourteenth Volume. P. D. Berger and H. M. Collins, eds. ASTM International, West Conshohocken, PA.

Rebollar-Alviter, A., Madden, L. V., and Ellis, M. A. 2007. Pre- and post-infection activity of azoxystrobin, pyraclostrobin, mefenoxam, and phosphite against leather rot of strawberry, caused by Phytophthora cactorum. Plant Dis. 91 559-564.

Rolando, C. A., Dick, M., Gardner, J., Bader, M. K.-A., and Williams, N. M. 2017. Chemical control of two Phytophthora species infecting the canopy of Monterey pine. For. Pathol. In press, doi:10.1111/efp.12327.

Rolando, C. A., Gaskin, R. E., Horgan, D. B., Williams, N. M., and Bader, M. K.-A. 2014. The use of adjuvants to improve uptake of phosphorous acid applied to Pinus radiata foliage. N. Z. J. Sci. 44:8.

Shearer, B. L., and Crane, C. E. 2009. Influence of site and rate of low-volume aerial phosphite spray on lesion development of Phytophthora cinnamomi and phosphite persistence in Lambertia inermis var. inermis and Banksia grandis. Australas. Plant Pathol. 38:288-304.

Shearer, B. L., and Fairman, R. G. 2007. Application of phosphite in a highvolume foliar spray delays and reduces the rate of mortality of four Banksia species infected with Phytophthora cinnamomi. Australas. Plant Pathol. 36: 358-368.

Stevens, P. J. G. 1993. Organosilicone surfactants as adjuvants for agrochemicals. Pestic. Sci. 38:103-122.

Thao, H. T. B., and Yamakawa, T. 2009. Phosphite (phosphorous acid): Fungicide, fertilizer or bio-stimulator? Soil Sci. Plant Nutr. 55:228-234.

Tynan, K. M., Wilkinson, C. J., Holmes, J. M., Dell, B., Colquhoun, I. J., McComb, J. A., and Hardy, G. E. S. J. 2001. The long-term ability of phosphite to control Phytophthora cinnamomi in two native plant communities of Western Australia. Aust. J. Bot. 49:761-770.

Wang, C. J., and Liu, Z. Q. 2007. Foliar uptake of pesticides-Present status and future challenge. Pestic. Biochem. Physiol. 87:1-8.

Williams, N., Graham, N., Suontoma, M., and Bader, M. K.-A. 2015. Screen current production lines of Pinus radiata for susceptibility to infection by Phytophothora pluvialis. New Zealand Forest Research Institute Limited, Rotorua, New Zealand. 